\title{
Prevention of Caribbean Electric Power Industry Accidents
}

\author{
Dr. Ganesh Narine Ph.D., M.Phil, MSc (Eng), BSc (Eng).
}

\begin{abstract}
The Caribbean is one of the foremost tourist destinations worldwide. Outside the region, information about the electric power industry and the working experiences of industry practitioners is not widely known. Electric power remains one of the most technically advanced, sophisticated, and challenging industries to manage safely. One of the biggest challenges is to prevent serious worker injuries and fatalities. The purpose of this study is to find solutions that can aid in the prevention of accidents in the Caribbean electric power industry and for workers to not become injured or killed. Actual data on the number of workplace accidents is difficult to source as there is no single repository of electric power industry accidents. The Bolman and Deal four-frame model was the conceptual framework for this study. The study, conducted through Survey Monkey, occurred over four rounds of a Delphi exercise. Participants were a panel of twelve Caribbean electric power industry managers, trainers, supervisors, professionals, and workers, each with 10-years or more experience. The aim was to record their solutions to serious and fatal workplace accidents. The NVivo 12 Plus software was used to analyze participant suggested solutions. Each issue in round one retained for further consideration were supported by six $\mathbf{( 5 0 \% )}$ ) or more participants indicating that it was an accident causing factor. Consensus after round one, occurred through scores of three or higher on a 5-point Likert-type scale for each issue, sanctioned by eight $\mathbf{7 0 \%}$ ) or more participants. In round two, participants suggested solutions they considered as desirable and feasible. In rounds three and four, the solutions were important and credible. Twenty-four different solutions were found in this study to prevent accidents based on Caribbean participants' responses.
\end{abstract}

Keywords — working experiences, desirable, feasible, important, credible

\section{INTRODUCTION}

Highlight An electricity industry worker in the Caribbean died when a branch from a tree that he was cutting fell on him (George, 2018). This worker was 32 years old and worked at the utility company for five years. There were 52 Occupational Safety and Health cases filed in the Industrial Court of Trinidad and Tobago in 2018 (Thomas-Felix, 2018). "There is a need for the melding of minds and hearts to re-examine and re-evaluate our common purpose and common goals and rededicate ourselves to the task of determining what we want our future and our society to be"

Dr. Ganesh Narine Ph.D., MPhil, MSc (Eng), BSc (Eng), is an electric industry engineer and manager with more than 30 years of experience in Generation, Transmission, Distribution, Engineering, Management, and Executive Management in the Caribbean (Trinidad and Tobago). He is now a Senior Manager at one of the largest electric utility companies in Canada. His research interest is in electric industry performance improvement and accident prevention.
(Thomas-Felix, 2016). The workplace accident experience in the electricity industry requires close examination, especially since this is an industry where workplace safety arrangements are sophisticated, with many experts, and accidents continue to occur (Manuele, 2014). Regardless of the Caribbean territory, leaders of the electric power industry have emphasized safety in the workplace. Despite this focus, workers continue to become seriously or fatally injured. Preventing these accidents are vitally important. This study is similar to an earlier research conducted in the United States and another study in Canada, where electric power industry practitioners as experts deliberated over four rounds in a Delphi exercise (Narine, 2019a; Narine, 2019b). Participants in this current study were individuals with more than ten years of working experience in the electric power industry in the Caribbean. The conceptual framework is the Bolman and Deal four-frame model (Narine, 2019a; Narine, 2019b).

\section{BACKGROUND}

Workplace safety is an issue that can become challenging and unmanageable if not built on a robust framework where the roles and responsibilities of all individuals at work are clearly established and consistently practiced. In the electric power industry, worker knowledge grows from training, work exposure and situations, and arrangements. Explicit knowledge develops from organizational social reality, work procedures, standards, technical documentation, equipment manufacturer instructions and manuals, and classroom training exercises (Aboagye-Nimo, Raiden, King, and Tietze, 2015). Fordyce et al. (2016) suggested that workplace trainers can enable worker appreciation of how dangerous electrical industry work is and how to adopt the best ways of mitigating hazards and danger. Hazards that workers are trained to recognize and mitigate, usually factor in accidents where the victims suffer serious injuries or are killed (Fordyce et al., 2016). Employee beliefs regarding organizational safety provisions and their effectiveness are critical indicators of how well promulgated and accepted the safety management systems are. The predominant impression is that workers in the electric power industry are well-trained, able to recognize hazards, and can mitigate these after assessing the associated risks (White et al., 2016). Worker knowledge is vital for organizational success: interpersonal communications, team building, critical thinking, active learning, and self-learning are all learned on the job, especially in settings where workers learn from one another (Aboagye-Nimo et al., 2015). Employees are more supportive of organizational change when that builds on a foundation they perceive as reasonable, inclusive, valid, and tolerable (Laberge et al., 2014). Employees who work around live power systems also work at heights where they can fall, or in confined spaces, that can be dangerous, which require specific detailed work procedures 
and arrangements. These individuals also work at remote locations and places where supervisors may or may not be present.

If accident investigators emphasize and only focus on human errors made by individuals just before an accident event, then the likelihood of preventing recurrence is significantly reduced (Dekker, 2006). Drupsteen, Groeneweg, and Zwetsloot (2013) purported that workers' performance improves when they are trained and if working arrangements are conducive to meaningful involvement and discussion. Managers influence workers' attitudes and behavior as individuals and in groups, and this can result in improved safety performance and organizational success (Griffin \& Curcuruto, 2016). Tucker, Ogunfowora, and Her (2016) extended this thinking and posited that CEOs could positively impact safe work performance by actively and genuinely embracing safety as a core organizational success factor, just like financial performance and production outputs. Mathieu, Neumann, Hare, and Babiak (2014) suggested that job satisfaction is directly related to performance outcomes and higher levels of job satisfaction do commensurate with improved performance outcomes. Employee job satisfaction and commitment depend on how leaders influence organizational social norms and culture, especially if they actively support meaningful involvement (Hayek, Thomas, Milorad, Novicevic, \& Montalvo, 2016).

\section{RESEARCH QUESTION AND CONCEPTUAL FRAMEWORK}

What do Caribbean electrical power industry experts regard as desirable, feasible, important, and credible solutions to workplace accidents where workers become seriously or fatally injured?

The Bolman and Deal four-frame model builds on four distinct frames or perspectives for assessing organizations, leadership, and issues that are important to that organization. These issues can range from organizational resilience, social interactions, ethical consideration, to cultural dynamics (Bolman \& Deal, 2013; Narine, 2019a; Narine, 2019b). The Structural Frame provides insight into organizational concepts of rules, roles, goals, policies, technology, and environment (Bolman \& Deal, 2013). The Human Resource frame is about needs, skills, and relationships concepts; the Political Frame focuses on power, conflict, competition, and organizational politics and; The Symbolic Frame is about culture, meaning, metaphor, ritual, ceremony, stories, and heroes (Bolman \& Deal, 2013; Narine, 2019a). The four-frame model was used to examine electric power industry organizations, leadership, management, and workers from the beliefs and understanding of experienced and active industry practitioners in the Caribbean. From that understanding, an identification of the deep underlying complex problems resulted, reasons for workplace accidents in the Caribbean electric power industry, and identification of possible solutions that can lead to the prevention of future accidents followed.

\section{ThE DELPHI TECHNIQUE}

Dalkey and Helmer (1963) indicated that the Delphi technique originated at the RAND Corporation in the 1950s. It is useful for conducting mixed methods, quantitative, and qualitative research. Participants remain anonymous to one another, only known to the researcher. The researcher must exercise control and be careful to maintain the research pre-conditions that are shared with the participants before the exercise begins. With this control, each participant could contribute to the study, based on their knowledge and understanding of the issues listed on the researcher set questionnaire (Narine, 2019a). Participants received by feedback from the researcher; and not from other participants (Linstone \& Turoff, 1975). The Delphi technique is useful and preferred in cases where information about the research topic was generally unknown, and the study focus was on solving an otherwise difficult-to-manage problem (Dalkey \&Helmer, 1963). Participants' opinions, beliefs, speculation, experience, and abilities were encouraged for information that the researcher analyzed to identify the emerging findings from the study. Linstone and Turoff (1975) indicated that the Delphi technique was preferred when participants were not usually involved in research work. The Caribbean electrical power industry participants in this study aptly exemplify that description of not usually involved in research.

In this study, the aim for consensus was that it could be achieved after Round 2 for desirable and feasible solutions to prevent electric power industry accidents. The consensus after round three was on the important solutions. In round four, the consensus was on credible solutions derived from the Delphi deliberations (Narine, 2019b). Issues moved from round one to round two once supported by six, $50 \%$, or more participants indicating that the issue was a causal factor in workplace accidents. Participants provided solutions that they believed were relevant to prevent future accidents. In round 2 and later rounds, each issue that proceeded to the next round if supported by eight participants or more selecting a score of three or more on a 5-point Likert type scale provided by the researcher. Eight participants represented more than $70 \%$ of the total number of participants in round two and subsequent rounds as used by Narine (2019b).

\section{PARTICIPANT SELECTION AND PERMISSION}

Each participant in this study were invited on public social media. The researcher sent seventy-five different invitations to individuals via LinkedIn, consistent with the procedures adopted by Narine (2019a). The pre-conditions for this study were shared via Survey Monkey, with each respondent to the original invitation. Once the individual agreed, they responded via Survey Monkey to indicate acceptance of the pre-conditions and to become a participant in this study.

Each of the twelve participants satisfied three criteria. They were employed in the electrical power industry in the Caribbean as a manager, supervisor, trainer, professional, or worker. Each individual was in this industry for ten years or more. Each individual had knowledge of and the effects of workplace accidents (Narine, 2019a).

The researcher administered questionnaires for the different Delphi rounds and all correspondence through 
Survey Monkey. There was a deliberate setting for responses to be anonymous even to the researcher. The only indicator the researcher had was the total number of responses received per round.

Seventy-five invitations went to invitees from Guyana, Trinidad and Tobago, St Kitts, Barbados, Cayman Islands, Jamaica, Bermuda, the Bahamas, and St Lucia. Table 1 and Table 2 show the demographic breakdown of Caribbean participants and demographic information. There were no participants from Jamaica, Bermuda, and the Bahamas.

Table 1.

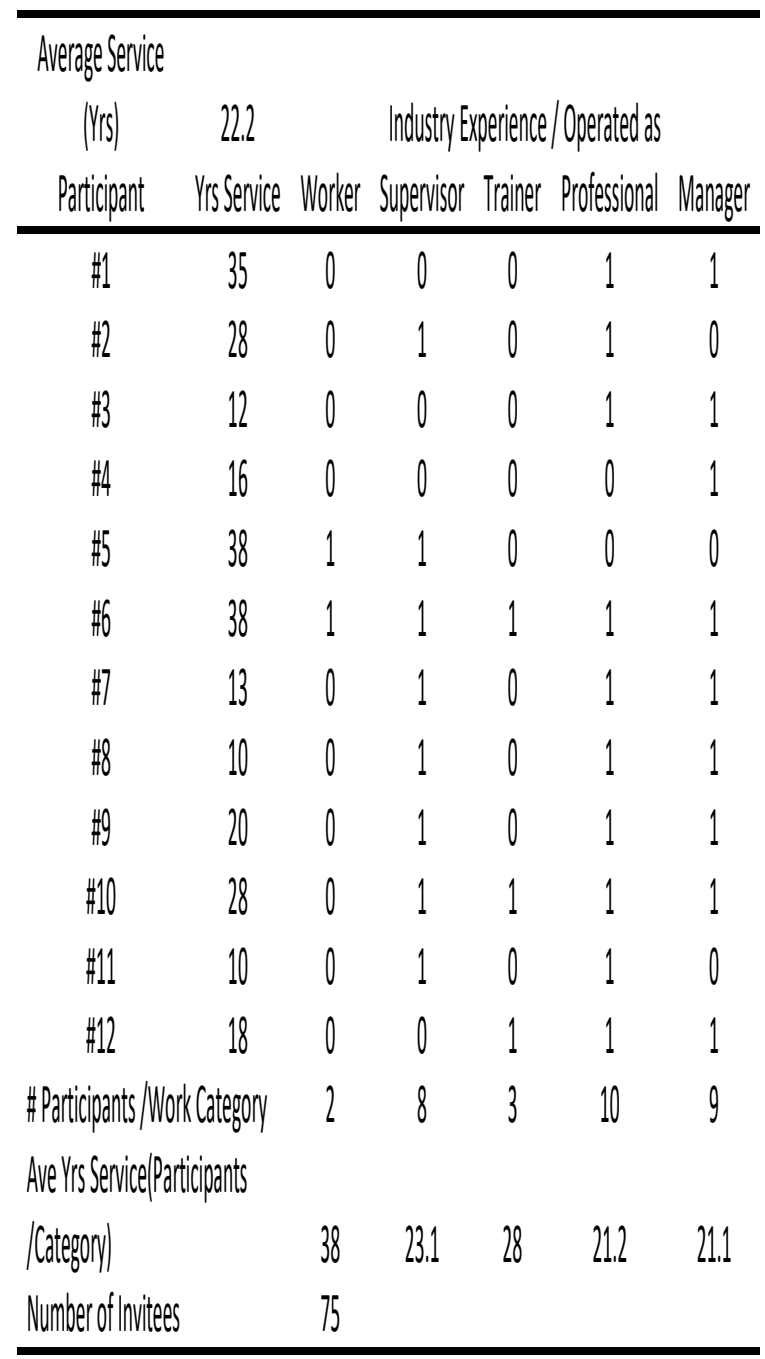

From Table 1, the average service years for participants in this study is 22.2 years. Two participants indicated that they worked for ten years; another two participants had 38 years of industry experience. Nine of the participants were managers, starting their careers at another level, and being promoted to this position afterward. Only two participants began their careers as workers, and neither remained at that level at the time of this study.
Table 2, Detailed Information on Participants

Added Demographic Details (Participants)

A. Senior Mechanical Maintenance Engineer

B. Field engineer for switching operations, issue of permits and supervise crews. Also coordinating switching operations on the transmission system.

C. Generation Manager/ Director for an Electricity Utility/Consultant for Power Utilities in the Caribbean

D. Executive Manager/Administration/Engineer Distribution/Communications

E. Senior Supervisor in charge of Live line \& Emergency. Respond to feeder trips and customers issues. Dispatch Crews.

\section{F. Lineman/Line Supervisor/Trainer/Managed work on Transmission \& Distribution Systems}

G. Manager/Senior Electrical Engineer/ job function entailed: Telecommunications system design, specification, procurement, installation and maintenance. And, particularly, the management of engineers to ensure the safety of all personnel involved in these tasks.

\section{H. Design Engineer/Advanced Field Coordinator/Manager of} electrical, high-risk and hazardous works.........supervise the installation, commissioning, maintenance, troubleshooting and repair of all protection and control equipment on the power system.

\section{Supervise mechanical maintenance from monthly,} intermediate to major overhauls. Manage generating station maintenance of electrical, mechanical, facilities, and welding and fabrication activities.

\section{J. HSE Professional /Engineer/Manager of HSE in electrical utility}

$K$. Engineer for planning and scheduling work, dispatching and managing overhead line and substation crews. Maintenance of the plant to prevent failures and maintain a high level of reliability while not compromising safety.

L. Manager, constructability, performance improvement, data analysis, training in the T\&D. 


\section{RESULTS}

Table 3 Round One Response

\begin{tabular}{|c|c|c|}
\hline Causal Factor in Electric Power Industry Accidents & $>49.9 \% \mathrm{Y}$ & Remark \\
\hline Q1: Poor Design & $\mathrm{N}$ & Dropped from study \\
\hline Q2: Management System Flaw & y & Proceed to Round 2 \\
\hline Q3: Poor Regulatory & $\mathrm{N}$ & Dropped from study \\
\hline \multicolumn{3}{|l|}{ Oversight } \\
\hline $\begin{array}{l}\text { Q4: Poor work ethics; history of wrongdoing that went } \\
\text { unaddressed }\end{array}$ & Y & Proceed to Round 2 \\
\hline Q5: Incorrect labeling & Y & Proceed to Round 2 \\
\hline Q6: Medical and other personal issues & Y & Proceed to Round 2 \\
\hline Q7: Grounding, earthing failures / errors & y & Proceed to Round 2 \\
\hline Q8: Ineffective and inefficient maintenance & Y & Proceed to Round 2 \\
\hline Q9: Animals / living organisms & N & Dropped from study \\
\hline Q10: Hazardous worksite conditions & Y & Proceed to Round 2 \\
\hline Q11: Unplanned events & N & Dropped from study \\
\hline Q12: Inappropriate work methods & Y & Proceed to Round 2 \\
\hline Q13: Stakeholder demands & N & Dropped from study \\
\hline Q14: Poor judgment by individuals or work crews & Y & Proceed to Round 2 \\
\hline Q15: Poor attitude and or behavior by individuals or work crews & y & Proceed to Round 2 \\
\hline Q16: Ineffective or no workplace training & y & Proceed to Round 2 \\
\hline Q17: Poor supervision & y & Proceed to Round 2 \\
\hline Q18: Work planning & Y & Proceed to Round 2 \\
\hline Q19: Management priorities & N & Dropped from study \\
\hline Q20: Poor team communication & Y & Proceed to Round 2 \\
\hline Q21: Willful disregard for safety rules & Y & Proceed to Round 2 \\
\hline Q22: Permit to work violations & y & Proceed to Round 2 \\
\hline Q23: Lock-out tag-out non-compliance & y & Proceed to Round 2 \\
\hline Q24: Organizational safety culture & y & Proceed to Round 2 \\
\hline Q25: Individual risk taking and negligence & y & Proceed to Round 2 \\
\hline Q26: Equipment failure & y & Proceed to Round 2 \\
\hline Q27: Procedural error & y & Proceed to Round 2 \\
\hline Q28: Poor management oversight & y & Proceed to Round 2 \\
\hline Q29: Poor quality material & Y & Proceed to Round 2 \\
\hline Q30: Non-use or personal protective equipment & Y & Proceed to Round 2 \\
\hline
\end{tabular}

There were 30 questions set by the researcher based on issues identified in previous studies on workplace accidents. Participants were asked to indicate whether they believed that the issue (one Issue per question) was a causal factor in Caribbean electric power industry accidents. Six issues, Poor Design, Poor Regulatory Oversight,

Animals/living organisms, Unplanned events, Stakeholder demands, and Management priorities were unsupported by more than six participants. These were, therefore, dropped from further consideration in this study.

Table 4 shows the number of participants' responses on desirable, feasible, important and credible solutions after round one.
Table 4.

\begin{tabular}{|c|c|c|c|}
\hline & $\begin{array}{l}\text { Desirable and } \\
\text { Feasible } \\
\text { Round } 2\end{array}$ & $\begin{array}{l}\text { Important } \\
\text { Round } 3\end{array}$ & $\begin{array}{c}\text { Confidence } \\
\text { Round } 4\end{array}$ \\
\hline S1 & Dropped from study & Dropped from study & Dropped from study \\
\hline S2 & 11 & 10 & 11 \\
\hline S3 & Dropped from study & Dropped from study & Dropped from study \\
\hline S4 & 11 & 10 & 11 \\
\hline S5 & 11 & 10 & 11 \\
\hline S6 & 10 & 8 & 10 \\
\hline S7 & 11 & 10 & 10 \\
\hline S8 & 10 & 10 & 10 \\
\hline S9 & Dropped from study & Dropped from study & Dropped from study \\
\hline S10 & 10 & 10 & 9 \\
\hline S11 & Dropped from study & Dropped from study & Dropped from study \\
\hline S12 & 11 & 10 & 11 \\
\hline S13 & Dropped from study & Dropped from study & Dropped from study \\
\hline S14 & 11 & 10 & 11 \\
\hline S15 & 11 & 10 & 11 \\
\hline S16 & 11 & 10 & 11 \\
\hline S17 & 11 & 10 & 11 \\
\hline S18 & 11 & 10 & 11 \\
\hline S19 & Dropped from study & Dropped from study & Dropped from study \\
\hline S20 & 11 & 10 & 11 \\
\hline S21 & 10 & 10 & 11 \\
\hline S22 & 10 & 10 & 10 \\
\hline S23 & 11 & 10 & 10 \\
\hline S24 & 11 & 10 & 11 \\
\hline S25 & 10 & 10 & 10 \\
\hline S26 & 10 & 10 & 10 \\
\hline S27 & 11 & 10 & 10 \\
\hline S28 & 11 & 10 & 11 \\
\hline S29 & 9 & 9 & 9 \\
\hline S30 & 11 & 10 & 10 \\
\hline
\end{tabular}

None of the issues after round one, from Table 4, was removed from consideration as they each were supported by eight participants or more to confirm the relevance of the issue and its solution to the prevention of workplace accidents, worker injuries, and fatalities in the Caribbean electric power industry.

\section{SOLUTIONS PROVIDED By PARTICIPANTS FROM THE CARIBBEAN}

1) Solution $\mathrm{S} 2$ for Issue 2 on Table 3: Involve the safety department and field crews for work processes and procedures review and revision. Manage follow-ups for temporary measures taken under emergency conditions and ensure that there are no quick fixes. Audit the corrective action taken and implement 'lessons-learned' for satisfactory completion.

2) Solution S4 for Issue 4: Promote a workplace accident prevention culture. Enforce strict compliance with safety rules and regulatory standards. Audit crew tasks, employee performance, attitudes, and behavior for expected organizational outcomes and standards. Review the organization's human resource process regarding personnel selection and promotion procedures, and its implementation. Maintain organizational arrangement with initial and continuous employee safety training, monitoring, correction, feedback, and record-keeping.

3) Solution S5 for Issue 5: Labeling of equipment, particularly switching equipment, is essential and can lead to an improved sense of confidence for crews (e.g., being told that a line is isolated when it is indeed de-energized and 
isolated). That can also lead accident prevention involving the switching personnel. Defective equipment must be locked and tagged, without exception, and opening circuits to break load on switches that not designed for the same are prohibited (especially if discouraged by managers and supervisors). Labeling on small items can also lead to fatal accident prevention. Improper labeling of chemicals (e.g., for bee abatement) or drinking/washing water can lead to the prevention of human poisoning or improper use of chemicals. Insulated tools and equipment must be suitably labeled when tested; improper labeling of these can result in untested or expired tools/equipment being utilized by individuals or crews.

4) Solution S6 for Issue 6: The Safety Management System should guide the management of this issue. Medical issues can result in people being unable to comply with safety measures. Personal issues can result in distraction. Workers shall be encouraged to share issues with their supervisors without going into specific details, which might make them uncomfortable. Supervisors and managers must be empowered to remove workers from safety-sensitive positions when there is doubt about the individual being able to remain safe or to support the safety of others.

5) Solution S7 for Issue 7: ensure availability and use of appropriate instrumentation for workers to test and confirm the integrity of grounding and that grounding exercises are error-free. Provide training and re-training of all employees who perform this activity. Remove, for re-training or permanently, all individuals who are found in breach of grounding procedures and practices regardless of rank or experience.

6) Solution S8 for Issue 8: There should be strict compliance with standard maintenance practices and procedures. If this is not practical, then ensure that quick fixes done under emergency conditions are communicated to all frontline workers, updated on the work plans and diagrams, and rectified during the next maintenance cycle if not before.

7) Solution S10 for Issue 10: A correctly done Job Hazard Analysis will enable individuals at work to identify "Hazardous worksite conditions" and for sufficient control measures to be implemented. Work Areas cordoned off properly.

8) Solution S12 for Issue 12: Written work methods must support work methodologies, job safety requirements, and reasonable precautions for identifying, eliminating, or controlling risk. When a particular job, or series of jobs, has never been previously performed then only well qualified, trained, and experienced planning teams must be engaged.

9) Solution S14 for Issue 14: Employee training and accountability, through recorded and traceable assessment, must follow set organizational procedures: notwithstanding employee experience. Involve frontline workers, supervisors, and managers when reviewing work procedures and practices. Ensure that all employees are trained and competent at recognizing challenging situations where they should seek assistance and or advice before attempting work and during the work exercise.

10) Solution S15 for Issue 15: Organizational Leadership must encourage all at work to remain focused on the job requirements. Supervisors and managers must discourage individual and group complacency and negligence due to overconfidence and risk-taking behavior. Equally, supervisors and managers must encourage individuals and working groups to support positive interaction on work-related activities, especially on challenging and difficult tasks.

11) Solution S16 for Issue 16: Workers must receive adequate and appropriate training: Standards need to be set for worker training on both skilled and unskilled functions. That focus starts from the recruitment level, ensuring that potential workers to be employed have the necessary aptitude and competence to be trained. The training program employed must be assessed and developed with the learning outcomes as a guide. Once workers receive training, a re-training and refresher schedule must be developed to remind workers of proper work methods and safe practices. Training must encompass all aspects of the job, including job hazard analysis.

12) Solution S17 for Issue 17: Organizational leaders and managers must require and support supervisors to consistently monitor performance and give feedback to workers. Supervisors must use opportunities for timely intervention to prevent near misses/accidents. Supervisors must be technically proficient, mature, and knowledgeable about work-related standards, policies, and procedures. Supervisors who do not enforce strict compliance with work-related rules and safety procedures shall be relieved of supervisory responsibilities or removed from the employ altogether.

13) Solution S18 for Issue 18: The work planning process must include a safety planning for all jobs, pre-job hazard identification, and risk assessments for all job functions and work tasks performed by employees so that they remain protected against undue risks while performing work.

14) Solution $S 20$ for Issue 20: Supervisors must issue work instructions that are consistent, simple to understand, and interactive whereby the worker must repeat or explain in their own words, the instruction for confirmation and clarity. All individuals at work must receive appropriate training on interpersonal communication. All individuals at work must comply with workplace requirements. Inter-personal issues that can hinder safe work must be declared, without exception, to the supervisor. All individuals at work must ensure the transfer of detailed information to other individuals, especially during changes of shifts, holidays, before, during, or after equipment tests, and on design / operational changes.

15) Solution S21 for Issue 21: Safety rules are carefully conceived and implemented to minimize work hazards. Managers and supervisors must reject deviance, recklessness, and never permit individual or group disregard of safety rules. Managers and supervisors who do not uphold strict compliance with work safety rules and procedures shall be dismissed from the employ of the 
organization. Workers not strictly and stringently following work safety rules shall also be dismissed.

16) Solution S22 for Issue 22: Permit to work systems is necessary for worker safety. It is a method of communication between two parties, such as plant operators and the executing crew, to indicate that the item of the plant to be worked on and that it is safe. The IDITE process is usually the prerequisite to a cold line permit. The permit is also a guide to follow the IDITE process correctly. Organizational leaders, managers, supervisors, and workers must strictly enforce and follow permit to work arrangements: defaulting individuals dismissed from the organization.

17) Solution S23 for Issue 23: This is a particular precaution that serves not only as a form of communication but also as a physical prevention for switching equipment operation when working on apparatus: Mitigates human error by other plant operators. Managers and supervisors must enforce strict-compliance with lock-out tag-out procedures to promote safe equipment operations and so prevent accidents and worker injuries.

18) Solution S24 for Issue 24: The CEO must make organizational safety culture as a personal mandate and lead from the front. Leadership and management must be pragmatic and support active organizational safety culture. Leaders and managers discussing requirements for good work ethics, the consequences for poor attitudes, and management priorities are paramount; especially when supervisors enforce safe work rules and procedures consistently.

19) Solution S25 for Issue 25: Proper pre-planning of work, enabling workers to call for assistance when necessary, facilitating open discussions on work to understand why challenging situations occurred, and mitigating the risks will prevent risk-taking situations and negligence. Supervisors must confront and address all situations and cases where individuals and crews deviated from set work rules and procedures. Organizational leaders and managers must consistently support supervisor actions to prevent individual risk-taking and negligence.

20) Solution S26 for Issue 26: Managers and supervisors must guarantee a very active and pro-active maintenance schedule and work arrangements. Workplace training review must occur for relevance. Workers must conduct work tasks consistent with OEM requirements, industry technical standards, and best practices, as well as organizational rules and procedures.

21) Solution S27 for Issue 27: Conduct meticulous review of selection criteria for dangerous work. Provide workers with and manage workplace training arrangements. Strictly enforce organizational work rules and procedures. Encourage workers, supervisors, and managers to review completed work together for lessons to be learned on challenging tasks and unforeseen challenges. Review work rules for relevance and ensure that each rule is simple to follow. Review toolbox talks and institute a system for recording such in worker training.

22) Solution S28 for Issue 28: Organizational leaders, managers, and supervisors must lead by example. They must possess knowledge of industry standards, work rules, procedures, and environmental conditions. Workers must be able to communicate effectively on and about worksite difficulties and problems, for managers and supervisors to initiate appropriate support for successful outcomes, including safe work, accident prevention, and injury-free results.

23) Solution S29 for Issue 29: Organizational leaders and procurement managers must align with workplace, and industry technical standards for the optimal quality product purchase. Technical professionals must ensure that items are tested and deemed acceptable before item-release for field use. Arrangements must exist and be functional for adequate and appropriate spares (volume and quality) to be available at times when and where needed. All workers shall receive training on the best material handling techniques. Equipment testing and other data must be kept and used for maintenance planners to review.

24) Solution S30 for Issue 30: Organizational leaders and managers must consistently support supervisor actions to prevent individual negligence on non-use of PPE. All individuals at work shall strictly follow all work rules and procedures requiring the use of PPE: Any individual who breaches these requirements shall be removed from dangerous work and dismissed from the organization.

\section{DISCUSSION}

The researcher identified thirty issues as factors that contributed to workplace accidents and presented them to the participants over four Delphi rounds. Participants deemed six of the thirty issues as not a contributor to workplace accidents. The six issues were, therefore, not dropped from consideration after one round. It is necessary, however, to list actual responses from participants to support the significance of this study.

1) One Caribbean participant in response to Issue 2 confirmed that " a flaw in the Safety Management System could lead to a systematic lack of oversight on safety-related issues." Another response to this question was that "A proper Safety Management System must also be reviewed and updated regularly to incorporate advancements in technology and changes in best practice."

2) For Issue 4 on poor work ethics, one response was that "We had a history of employees with very poor work ethics, performing tasks improperly, signing off on jobs as completed when it was not done." Another response was, "In one incident, a crew signed off a work order confirming that the battery supply utilized to supply the protection relays in a substation was serviced and in proper condition. One day later, a fault developed on a distribution circuit from this station. The protection relays failed to operate due to no dc supply from the batteries, and as a result, the breaker did not open to isolate the fault, and there was an explosion and fire that destroyed the substation. Investigations revealed that the batteries were not serviced as indicated by the maintenance crew." 
3) For Issue 5, one participant indicated "switching on defective equipment that is not locked and tagged as defective, and breaking load on switches not designed for same can lead to serious and fatal accidents."

4) For Issue 6, one response was, "One heavy equipment driver/operator was suffering from a heart condition unknown to him. He experienced a heart attack and succumbed to his condition while on active duty. Fortunately, he was not driving or operating the utility truck at the time."

5) For Issue 7, one participant suggested, "In the event of a breakdown of the insulation or the energized infrastructure becoming dislodged from the insulating infrastructure and making contact with the support structure; proper bonding ensures low touch potentials for anyone making contact with the support structure at the time. Improper bonding can result in a large touch potential, which can be fatal."

6) For Issue 8, one response included "A substation crew serviced a Ring Main Unit and reported that all work was completed. Shortly after that, a supervisor operated the oil switch on the said Ring Main Unit. The switch exploded, and the supervisor suffered third-degree burns. He subsequently died from his injuries."

7) For Issue 10, "The respondent is unaware of any incidences where "Hazardous worksite conditions" was a causative factor in serious or fatal accidents" was one response.

8) For Issue 12, "A contractor installed a pole and down guy. The guy anchor was installed incorrectly, and the following day the guy anchor, rod, and span wire uprooted, causing the pole to lean and fall. The pole fell onto an oncoming minivan with twelve persons causing multiple serious injuries to the passengers and completely destroyed the minivan."

9) For Issue 14, "There was a fatality recently involving a line clearing crew member who took the decision to utilize a porter wrap to cut a large branch without taking a proper assessment. This eventually led to an improper technique being utilized for the size of the branch resulting in the branch falling on one of the line clearers, killing him instantly."

10) For Issue 15, "As discussed before, this is tied into work ethic. Complacency on the job has to be managed properly by the supervisor. Also, drug and alcohol abuse has lead to accidents where workers are not fully cognizant."

11) For Issue 16, "We preach safety in everything we do. April is considered Health \&Safety Month where I work, and we have a "Go zero" pledge."

12) For Issue 17, "The supervisor is directly responsible for the work methods employed, poor attitudes and work ethics of members of the work party and bad decision making by him or members of the crew."

13) For Issue 20, "Two technicians were performing testing on a Power Transformer in a substation. The work crew was using a Hi-pot test set. Employee 'A' was standing at the top of the transformer with the test set leads while Employee 'B' was at ground level operating the test set. The team had just completed an Insulation Resistance Test on one component. Employee 'A' wanted to remove the test leads to reposition same to another component to commence another test. He used the word "okay" to signal his intent to remove the leads to Employee ' $B$ '. Employee ' $B$ ' thought Employee 'A' was telling him to switch on the test set. He switched on the set as Employee 'A' was removing the leads, and Employee 'A' received an electrical shock and burns to his hands."

14) For Issue 21, "An employee failed to test to confirm the status of a circuit energized at $12 \mathrm{kV}$ and attempted to apply an earth on the circuit. There was a flashover and an explosion, the employee, suffered burns and temporary hearing loss. The feeder also tripped."

15) For Issue 22, "An employee received a Permit to Work identifying the limits of the outage as between ABS \# $A A A$ and $A B S \# B B B$. The employee attempted to install a steel pole beyond $A B S$ \# BBB. The pole touched the lines, and there was a flashover. The crew violated the limits of the permit."

16) For Issue 23, "An ABS was found to have one defective blade. To maintain the supply on that phase a jumper was placed on that blade. The ABS was not tagged and locked out. Some time after another fault occurred on that circuit at $2.00 \mathrm{am}$, causing conductors to fall to the ground. The breaker at the substation operated isolating the feeder. A crew responded, and the supervisor opened the said ABS to isolate the faulted section, not knowing that one phase was jumpered. The supervisor then reclosed the breaker at the substation via remote switching. The phase with the jumper was re-energized, and an employee received burns and subsequently lost the limb."

17) For Issue 24, "I have worked with a company that was experiencing daily and weekly recordable accidents, however, when the CEO made it his mandate and lead from the front, there was no incident up to two years and counting."

18) For Issue 25, "An employee attempted to apply earths to an overhead line. He did not test the circuit to confirm it was de-energized, and he did not use a hot stick to install the earth set, he attempted to do so using his bare hands. The circuit was still energized, and he received an electrical shock and third-degree burns. He subsequently lost a hand and a foot."

19) For Issue 26, "Equipment like bucket trucks where a lineman is in one while executing his work and the truck fails in some form or fashion can lead to serious accidents."

20) For Issue 27, "A crew was attempting to fell a tree that was in contact with an overhead line. This was a large tree weighing several tonnes. The girth of the trunk of the tree was approximately 8 feet. The crew failed to follow the proper procedure for first reduce the weight of the tree by removing the limbs before cutting the main trunk. They attempted to cut the entire tree at once using a hoist to control the descent of the tree. The hoist could not support the weight of the tree, and the tree fell on a member of the public, killing him."

21) For Issue 28, "Repeated accidents must be attributable to poor management oversight."

22) For Issue 29, "A poor quality ball end link supporting a $66 \mathrm{kV}$ conductor failed, and the conductor fell damaging several passing vehicles." Another response was, "An example would be a pin type insulator changeout using hotline with the new insulator failing when the put into service. This happened recently, and upon investigation, 
it was revealed that a batch of pin type insulators received was defective. Even though it passed an insulation resistance test, it was made of a soft material that was cut easily by the tie wire."

$23)$ For Issue 30, "An employee attempted to operate an Air Break Switch without any PPE. As the switch was opened, heavy arcing occurred, and the employee suffered fatal electrical burns and shock."

\section{CONCLUSION}

This study is vitally important and can prove useful in the prevention of accidents that are occurring in the Caribbean electrical power industry: It is a repository of useful information for practitioners and interested parties to reference the performance of their organizations and for individuals at work to remain injury-free.

Twenty four different causal factors for accidents are identified. Solutions to each of these are listed. Leaders and managers in the Caribbean can easily measure their experience with workplace accidents and to improve performances where necessary.

Participants in this study agreed that each leader, manager, supervisor, and worker can prevent accidents. Management and supervision communicating workplace priorities, and enforcing compliance with set policies, work procedures, and rules, can positively change organizational outcomes and performance.

\section{REFERENCES}

[1] Aboagye-Nimo, E., Raiden, A., King, A. and Tietze, S., 2015. Using tacit knowledge in training and accident prevention. Proceedings of Institution of Civil Engineers: Management, Procurement and Law , 168(5), pp.232-240. Available at: http://dx.doi.org/10.1680/mpal.1400027.

[2] Bolman, L. G., \& Deal, T. E., 2013. Reframing organizations: Artistry, choice, and leadership (5th ed.). San Francisco, CA: Jossey-Bass.

[3] Dalkey, N., \& Helmer, O., 1963. An experimental application of the Delphi method to the use of experts. Management Science, 9(3), pp 458-467. Available at: http://dx.doi.org/10.1287/mnsc.9.3.458

[4] Dekker, S., 2006. The field guide to understanding human error. Ashgate Publishing, Farnham.

[5] Drupsteen, L., Groeneweg, J., \& Zwetsloot, G. I., 2013. Critical steps in learning from incidents: using learning potential in the process from reporting an incident to accident prevention. International Journal of Occupational Safety and Ergonomics, 19(1), pp 63-77. Available at: http://dx.doi.org/10.1080/10803548.2013.11076966.

[6] Fordyce, T. A., Leonhard, M. J., Watson, H. N., Mezei, G., Vergara, X. P., \& Krishen, L., 2016. An analysis of fatal and non-fatal injuries and injury severity factors among electric power industry workers. American Journal of Industrial Medicine, 59(11), pp 948-958. Available at: http://dx.doi.org/10.1002/ajim.22621

[7] George, K. 2018. Tree branch kills TTEC worker. The Newsday, Retrieved https://newsday.co.tt/2018/08/11/tree-branch-kills-ttec-worker/

[8] Griffin, M. A., \& Curcuruto, M., 2016. Safety climate in organizations. Annual Review of Organizational Psychology and Organizational Behavior, 3, pp 191-212. Available at: http://dx.doi.org/10.1146/annurev-orgpsych-041015-062414

[9] Hayek, M., Thomas, C. H., Novicevic, M. M., \& Montalvo, D., 2016. Contextualizing human capital theory in a non-western setting: Testing the pay-for-performance assumption. Journal of Business Research, 69(2), pp 928-935. Available at: http://dx.doi.org/10.1016/j.jbusres.2015.06.039

[10] Laberge, M., MacEachen, E., \& Calvet, B., 2014. Why are occupational health and safety training approaches not effective? Understanding young worker learning processes using an ergonomic lens. Safety Science, 68, pp 250-257. Available at: http://dx.doi.org/10.1016/j.ssci.2014.04.012
[11] Linstone, H. A., \& Turoff, M., 1975. The Delphi method: Techniques and applications. Reading, MA: Addison-Wesley.

[12] Manuele, F. A., 2014. Incident investigation our methods are flawed. Professional Safety, 59(10), 34. Available at: http://www.asse.org

[13] Mathieu, C., Neumann, C. S., Hare, R. D., \& Babiak, P., 2014. A dark side of leadership: Corporate psychopathy and its influence on employee well-being and job satisfaction. Personality and Individual Differences, $59, \quad$ pp 83-88. Available at: http://dx.doi.org/10.1016/j.paid.2013.11.010

[14] Narine, G., 2019a. Causes and prevention of electric power industry accidents: A Delphi study. Available at https://scholarworks. waldenu.edu/cgi/viewcontent.cgi?article=8767\& context=dissertations

[15] Narine, G. 2019b. Electric power industry accident prevention in Canada. International Journal of Engineering and Technical Research (IJETR), 9(12), pp 23-30. Available at: https://www.erpublication.org/published_paper/IJETR2841.pdf

[16] Thomas-Felix, D., 2016. Special sitting of The Industrial Court of Trinidad and Tobago for the opening of the $2016-2017$ law term. Available at

[17] https://industrialcourt.org.tt , media-centre , speeches , download $=18: 201$..

[18] Thomas-Felix, D., 2018. Special sitting of The Industrial Court of Trinidad and Tobago for the opening of the 2018 - 2019 law term. Available at

[19] https://industrialcourt.org.tt , media-centre , speeches , download $=18: 201 \ldots$

[20] Tucker, S., Ogunfowora, B., \& Ehr, D., 2016. Safety in the c-suite: How chief executive officers influence organizational safety climate and employee injuries. Journal of Applied Psychology, 101(9), 1228 Available at: http://dx.doi.org/10.1037/ap10000116.

[21] White, K. M., Jimmieson, N. L., Obst, P. L., Gee, P., Haneman, L., O'Brien-McInally, B., \& Cockshaw, W., 2016. Identifying safety beliefs among Australian electrical workers. Safety Science, 82, 164-173. Available at: http://dx.doi.org/10.1016/j.ssci.2015.09.008

Author Dr. Ganesh Narine Ph.D., MPhil, MSc (Eng), BSc (Eng), is an electric industry engineer and manager with more than 30 years of experience in Generation, Transmission, Distribution, Engineering, Management, and Executive Management in the Caribbean (Trinidad and Tobago). He is now a Senior Manager at one of the largest electric utility companies in Canada. His research interest is in electric industry performance improvement and accident prevention. 